\title{
В.Ю. Музычук
}

Институт экономики РАН, Государственный институт искусствознания, Москва

\section{Финансирование культуры в России: шаг вперед и два назад...}

Аннотация. Статья посвящена анализу финансирования сферы культуры в России за последние два десятилетия как в целом по отрасли, так и в разрезе видов культурной деятельности. В работе проанализированы возможности государственных (муниципальных) учреждений культуры по зарабатыванию собственных доходов, а также по привлечению благотворительных и спонсорских средств по типам учреждений (театры, концертные организации, музеи, библиотеки и клубы). Существующая ситуация с финансированием культуры в России характеризуется как сохранение остаточного принципа финансирования, низкий приоритет культуры в макроэкономической политике государства, превалирование прямого бюджетного финансирования, несовершенство институциональной среды для привлечения внебюджетных средств государственных (муниципальных) учреждений культуры. Несмотря на отдельные попытки построения многоканальной системы финансирования культуры, предпринятые за последнюю четверть века, палитра возможностей внебюджетного финансирования по-прежнему монохромна. Создание многоканальной системы финансирования культуры в России требует серьезной налоговой реформы, реформы местного самоуправления, а также отхода от чисто бухгалтерского подхода, при котором развитие тормозится в угоду поддержания существующего статус-кво.

Ключевые слова: экономика культуры; государственная поддержка культуры; расходъ на культуру; культурная политика; благотворительность в сфере культуры.

Классификация JEL: Z1, Z18.

DOI: $10.31737 / 2221-2264-2019-41-1-10$

Прошло более четверти века с момента распада Советского Союза и становления России как суверенного государства. И если в СССР культура финансировалась по остаточному принципу преимущественно за счет средств государственного бюджета, то в новой России предполагалось существенно увеличить объемы финансового обеспечения путем создания многоканальной системы финансирования культуры. Речь шла не только о необходимости увеличения объемов бюджетного финансирования (закреплении нормативов государственного финансирования по уровням власти), но и появлении новых источников за счет так называемой косвенной поддержки: частной и корпоративной благотворительности, спонсорских средств, развитой системы налоговых преференций, введения специальных (маркированных) налогов, проведения национальных лотерей, создания эндаумент-фондов (фондов целевого капитала) и т.п. В данной статье предпринята попытка проанализировать произошедшие изменения в системе финансового обеспечения сферы культуры как с точки зрения диверсификации источников финансирования, так и трансформации институциональной среды.

\section{Вводные замечания}

Показатели финансирования культуры и кинематографии из консолидированного бюджета РФ за период 1991-2017 гг. рассчитаны на основе данных, публикуемых в Российском статистическом ежегоднике ${ }^{1}$ в разделе «Финансы» (государственные финансы / расходы консолидированного бюджета РФ на социально-культурные мероприятия) за 1991-2004 гг., а также на основе данных об исполнении консолидированного бюджета РФ за 2005-2017 гг., публикуемых на сайте Федерального казначейства $Р \Phi^{2}$.

Расходы на культуру и кинематографию (\% от ВВП России) за рассматриваемый период рассчитаны на основе значений

1 См. материалы сайта http://www.gks.ru.

2 См. материалы сайта http://www.roskazna.ru. 
валового внутреннего продукта Российской Федерации за соответствующие годы, публикуемых Росстатом.

Расходы на культуру и кинематографию в совокупных расходах консолидированного бюджета РФ за рассматриваемый период (в реальных (сопоставимых) ценах) рассчитаны на основе значений индекса-дефлятора ВВП за соответствующие годы, публикуемых Росстатом.

Расходы на культуру и кинематографию в совокупных расходах консолидированного бюджета РФ за рассматриваемый период (в расчете на душу населения) рассчитаны на основе значений численности населения Российской Федерации за соответствующие годы, публикуемых Росстатом.

Расходы по видам культурной деятельности (театры, концертные организации, музеи, библиотеки, культурно-досуговые учреждения, культурное наследие), доходы от уставной деятельности, благотворительные вложения и спонсорские средства государственных (муниципальных) учреждений культуры приведены по данным ГИВЦ Минкультуры России за соответствующие годы.

\section{Объемы финансирования культуры}

В 2017 г. расходы из консолидированного бюджета (КБ) РФ по статье «Культура и кинематография» составили 492,9 млрд руб. (с учетом межбюджетных трансфертов 499,9 млрд руб.), что соответствует $0,54 \%$ ВВП и $1,52 \%$ в совокупных расходах КБ РФ. В расчете на душу населения расходы на культуру составили 3357,6 руб. на человека в год (или 50,85 евро по среднегодовому курсу рубля к евро в 2017 г.).

Темпы роста расходов на культуру за период 1991-2017 гг. четко демонстрируют три временных диапазона в динамике государственного финансирования (рис. 1):

- 1991-2004 гг., в течение которого удалось преодолеть последствия тяжелейшего для России социально-экономического кризиса середины 1990-х годов. Только в 2004 г. удалось довести объемы финансирования культуры до уровня 1991 г.;

- 2004-2008 гг., который без преувеличения можно назвать золотой пятилеткой финансирования культуры. Это период наращивания расходов на культуру, что нашло отражение в широкой палитре разнообразных культурных достижений. За 5 лет удалось увеличить объем финансирования культуры в 1,7 раза в реальном выражении. В Концепции-2020, разработка и утверждение которой пришлись на 2008 г., предусматривалось доведение расходов на культуру до 1,5\% ВВП при реализации оптимистического сценария.

- 2008-2017 гг., когда темпы роста финансирования культуры дрейфуют в диа-

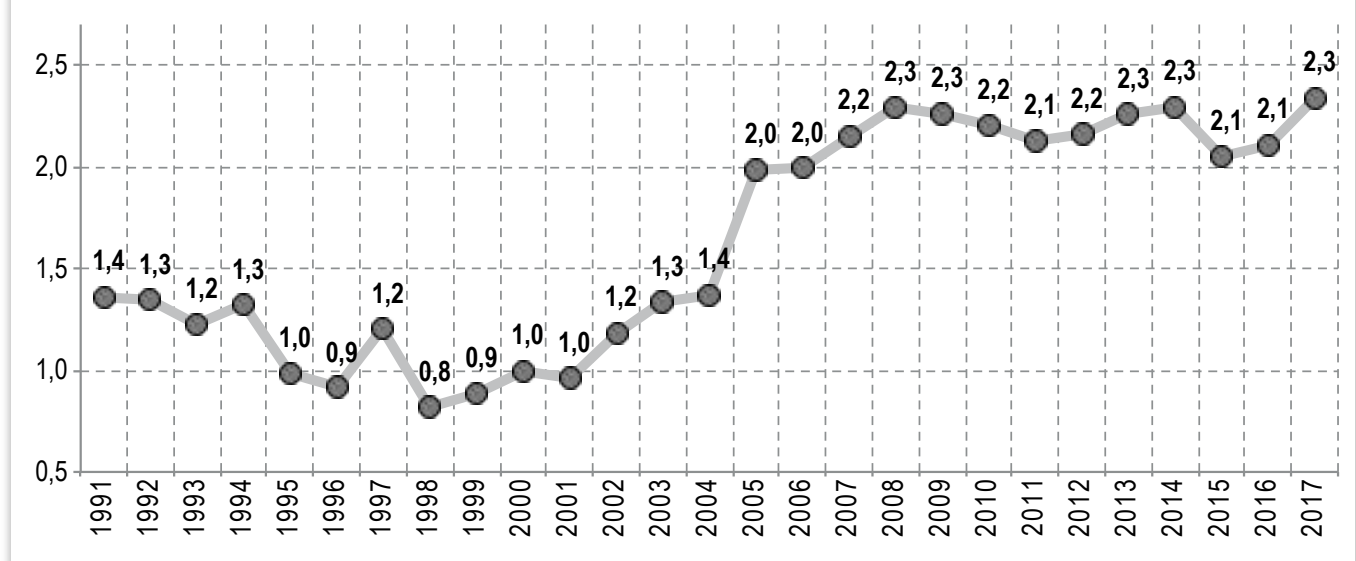

Рис. 1

Темпъ роста расходов на культуру и кинематографию из консолидированного бюджета РФ (1991-2017 г2.) в сопоставимых иенах (2000 г. = 1), раз 
пазоне от 2,1 до 2,3 раза от уровня 2000 г. Начиная с 2009 по 2011 г. наметился спад в объемах финансирования культуры в реальном выражении, после чего в течение 20122014 гг. удалось вернуться к уровню 2008 г. В 2015 г. расходы на культуру сократились не только в реальном, но и номинальном выражении, что нашло свое отражение практически во всех основных показателях финансирования культуры. В 2017 г. объем финансирования культуры в реальном выражении стал сопоставим с уровнем 2008-2009 гг., т.е. 8-9-летней давности.

Ситуация с финансовым обеспечением сферы культуры демонстрирует наличие управленческого провала в части захвата чужих компетенций Минфином России (Рубинштейн, Городецкий, 2017). Минкультуры России не в состоянии обеспечить увеличение расходов на культуру в виду установленных Минфином России правил игры. В результате реализация культурной политики и государственная поддержка культуры являются не самостоятельными направлениями политики государства в области культуры, а лишь производными от бюджетного процесса.

\section{Финансирование культуры в разрезе основных статей бюджетной классификации расходов}

Приоритетность социальных целей и приверженность государства к их достижению прослеживается в структуре расходной части государственных бюджетов (табл. 1). Структура государственных расходов России в 2017 г. демонстрирует несколько другую шкалу приоритетов (рис. 2).

В России суммарно на оборону и правопорядок приходится практически такой же объем бюджетных средств (15\%), сколько на образование и здравоохранение вместе взятые (19\%). В среднем по странам ОЭСР данные статьи расходов занимают соответственно 9,4\% против $31,3 \%$ в структуре государственных расходов. Другими словами, суммарные расходы на образование и здравоохранение в три раза превышают расходы на оборону и правопорядок в среднем по странам ОЭСР.

От того, чему отдается предпочтение при выработке макроэкономической политики - силовому блоку или человеческому капиталу, - реально зависит вектор социально-экономических преобразований в стране. В отно-

\section{Таблица 1}

Структура государственных расходов в отдельных странах ОЭСР, 2015 г., \%

(государственные расходы, всего $=100 \%$ )

\begin{tabular}{|c|c|c|c|c|c|c|c|}
\hline Страны & 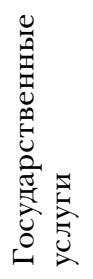 & 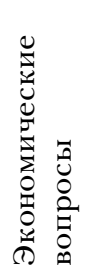 & 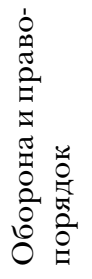 & 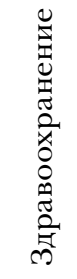 & 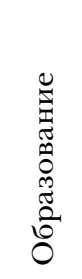 & 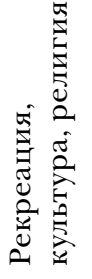 & 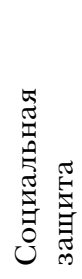 \\
\hline Финляндия & 14,9 & 8,3 & 4,6 & 12,6 & 11,0 & 2,6 & 44,9 \\
\hline Франция & 11,0 & 10,0 & 6,0 & 14,3 & 9,6 & 2,3 & 43,1 \\
\hline Германия & 13,5 & 7,1 & 5,9 & 16,3 & 9,6 & 2,3 & 43,1 \\
\hline Италия & 16,6 & 8,1 & 6,1 & 14,1 & 7,9 & 1,5 & 42,6 \\
\hline Швеция & 14,1 & 8,4 & 4,9 & 13,8 & 13,0 & 2,2 & 41,6 \\
\hline Великобритания & 10,6 & 7,1 & 9,7 & 17,8 & 12,0 & 1,5 & 38,4 \\
\hline США & 13,8 & 8,7 & 14,2 & 24,2 & 16,2 & 0,7 & 20,8 \\
\hline В среднем по OECD & 13,2 & 9,3 & 9,4 & 18,7 & 12,6 & 1,5 & 32,6 \\
\hline
\end{tabular}




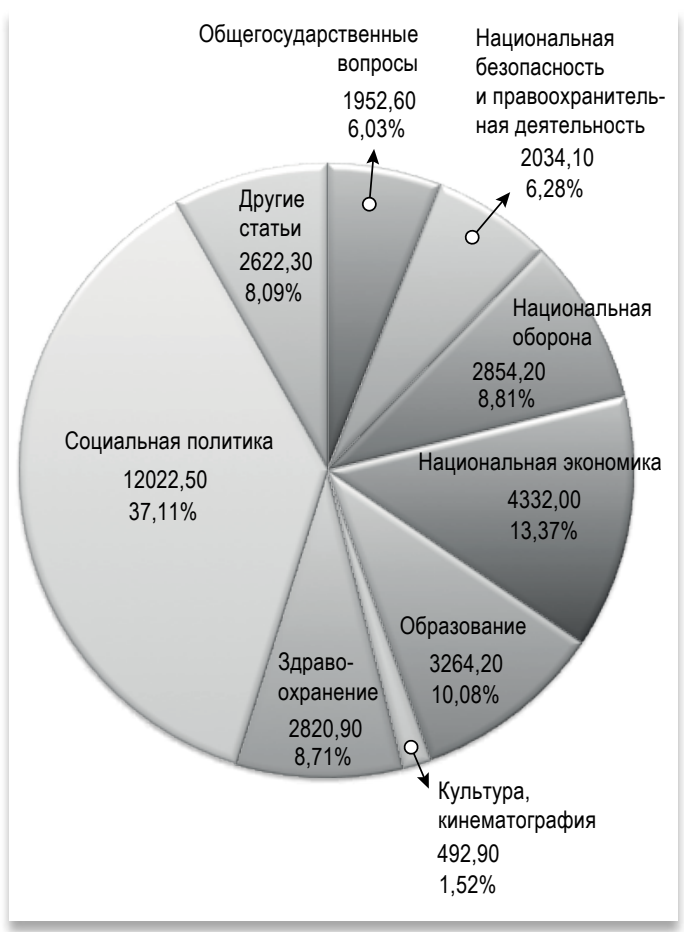

Puc. 2

Структура расходов консолидированного бюджета РФ в 2017 г., млрд руб. и \%

шении остаточного финансирования сферы культуры речь идет не о дефиците бюджетных средств, а о низкой приоритетности культуры в рамках макроэкономической политики государства. Но без изменения пропорций расходных статей государственного бюджета задача активизации человеческого капитала и опережающего развития гуманитарного сектора экономики становится трудновыполнимой.

\section{Структура финансирования по направлениям культурной деятельности}

396,5 млрд руб., выделенных из консолидированного бюджета РФ по статье «Культура и кинематография» в 2015 г., были распределены следующим образом: $21 \%$ - на культурно-досуговые учреждения (101,0 млрд руб.); по 11\% на театры (51,8 млрд руб.) и библиотеки (51,3 млрд руб.); $10 \%$ - на музеи (49,5 млрд руб.); 4\% - на концертные организации (18,8 млрд руб.); 8\% - на проведение ремонтно-реставрационных работ на объектах культурного наследия; оставшиеся 33\% - на прочие цели и виды деятельности (рис. 3).

Структура распределения финансовых средств очень не сбалансирована. На финансирование 615 театров выделяется такой же объем государственных средств, что и на содержание 39 тысяч библиотек. В самом уязвимом положении находятся библиотеки и объекты культурного наследия (порядка 178 тыс. памятников, включая объекты археологии, поставленных на государственный учет). В отношении библиотек речь идет не только о неудовлетворительном состоянии зданий, но и о хроническом отсутствии средств на пополнение и обновление библиотечных фондов. Львиная доля выделяемых средств идет на оплату труда библиотечных работников. В ситуации с сохранением объектов культурного наследия получается, что выделяемых средств хватает на проведение ремонтно-реставрационных работ на $4 \%$ объектов в общем количестве памятников, находящихся на государственной охране. При этом в «Стратегии государственной культурной политики РФ на период до 2030 г.» говорится о том, что только $39 \%$ памятников федерального значения находятся в удовлетворительном состоянии. По данным ВООПИК, Россия ежегодно теряет порядка 200 памятников.

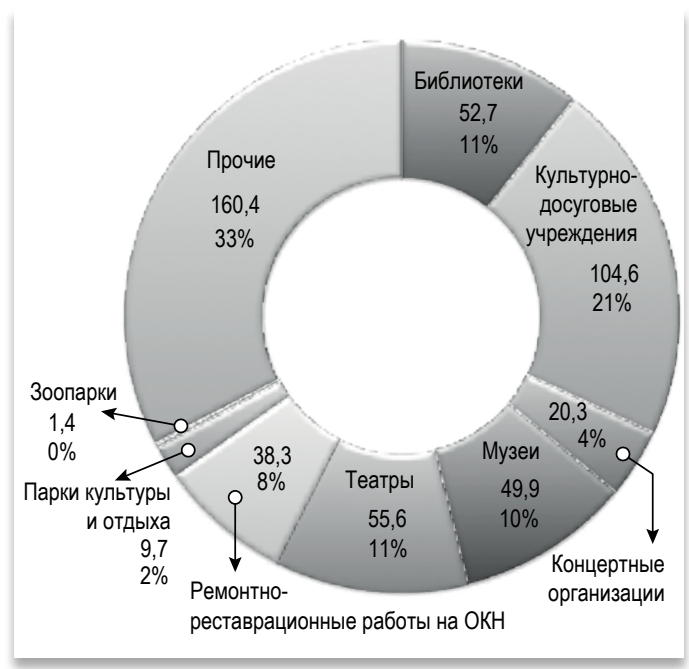

Рис. 3

Распределение бюджетного финансирования сферы культуры в разрезе видов деятельности, 2015 г., млрд руб. и \% 
Таким образом, необходимо выявление горячих точек недофинансирования внутри сферы культуры с последующим нивелированием диспропорций финансирования по направлениям культурной деятельности.

\section{Международные сопоставления}

В целом с 2000 г. расходы на культуру и кинематографию из КБ РФ в расчете на душу населения увеличились в 2,3 раза в реальном выражении. Много это или мало? По показателю расходов на культуру в расчете на душу населения, равному в 2015 г. 40 евро (в расчете по среднегодовому курсу рубля к евро), Россия существенно отставала от развитых стран: Дании - в 8 раз (326 евро), Франции - в 6 раз (241 евро), Финляндии в 5 раз (202 евро), Германии - в 3,5 раза (142 евро), Великобритании - в 2,6 раза (105 евро), Италии - в 2,4 раза (96 евро) и т.д. Из стран Евросоюза мы опережали только Португалию (39 евро) и Румынию (35 евро) $)^{3}$. Подушевое финансирование культуры в размере 51 евро в 2017 г. в России достигнуто в большей степени за счет колебаний курса рубля к евро, нежели реального увеличения расходов.

\section{Превалирование прямого}

бюджетного финансирования

Финансирование выделяется на выполнение государственного (муниципального) задания государственным (муниципальным) учреждениям культуры. Расчет финансового обеспечения государственного задания осуществляется по принципу от обратного, т.е. обратным счетом, а не от реальных потребностей (Музычук, 2017). В последнее время качественные параметры государственного задания (например, для федеральных театров раныше был только один показатель - новые постановки, а теперь добавилась доля детского репертуара) чреваты вмешательством государства в творческую деятельность. Внедряемое в настоящее время нормирование труда в сфере культуры призвано оптимизировать бюджетные расходы. Учредитель в лице государства стремится нормировать производственный процесс подведомственных учреждений вплоть до канцелярских скрепок. Любые попытки введения косвенных форм финансирования культуры блокируются Минфином России на корню.

\section{Внебюджетные источники финансирования культуры}

В большинстве своем внебюджетные источники сводятся к собственным заработанным доходам от основных направлений уставной деятельности.

В настоящее время отмечается усиление тенденции к коммерциализации культуры, обусловленное требованием учредителя больше зарабатывать по отношению к подведомственным государственным (муниципальным) учреждениям культуры. Например, для театров доля бюджетного финансирования составляет в среднем $68 \%$ в общей сумме финансовых

Таблица 2

Внебюджетные источники финансирования по видам культурной деятельности, 2016 г.

\begin{tabular}{|l|c|c|c|}
\hline $\begin{array}{c}\text { Вид } \\
\text { культурной }\end{array}$ & $\begin{array}{c}\text { Доля бюджетного } \\
\text { финансирования в общей } \\
\text { сумме финансовых } \\
\text { поступлений, } \%\end{array}$ & $\begin{array}{c}\text { Доходы } \\
\text { от уставной } \\
\text { деятельности, } \\
\text { млрд руб. }\end{array}$ & $\begin{array}{c}\text { Доля доходов от уставной } \\
\text { деятельности в общей } \\
\text { сумме финансовых } \\
\text { поступлений, } \%\end{array}$ \\
\hline \hline Театры & 68,6 & 22,4 & 27,6 \\
\hline Музеи & 73,2 & 12,5 & 18,3 \\
\hline $\begin{array}{l}\text { Концертные } \\
\text { организации }\end{array}$ & 76,1 & 5,0 & 18,6 \\
\hline Библиотеки & 98,0 & 0,5 & 0,9 \\
\hline Клубы & 90,8 & 6,4 & 5,5 \\
\hline
\end{tabular}

${ }^{3}$ Рассчитано по данным статистической базы Eurostat в разделе «Государственные финансы». 
поступлений (2016 г.). Для успешных столичных и губернских театров эта доля не превышает 35-50\%, а львиная доля провинциальных театров демонстрирует размер данного показателя на уровне 80-90\%. Говорить о коммерческой успешности театров, ссылаясь на опыт востребованных публикой столичных театров, не представляется корректным.

Для библиотек и клубов возможности для зарабатывания средств сильно ограничены, поэтому их доля в общей сумме финансовых поступлений составляет соответственно 1 и 5,5\%, а доля бюджетного финансирования превышает отметку в $90 \%$ для библиотек (98\%) и клубов $(91 \%)$. Требовать от библиотек и клубов таких же объемов собственных заработанных доходов, как и у театров, не только нецелесообразно, но и контрпродуктивно.

\section{Благотворительные и спонсорские средства}

Еще одним важным источником в многоканальной системе финансирования сферы культуры являются благотворительные и спонсорские средства. В России их доля в общей сумме финансовых поступлений государственных (муниципальных) учреждений культуры минимальна (табл. 3).

В музеях и театрах доля благотворительных и спонсорских средств выше, чем в других организациях культуры, и составляет порядка $2 \%$ в общей сумме финансовых поступлений. Причем треть этих средств приходится на федеральные театры и музеи. В провинциаль- ных учреждениях культуры этот показатель очень мал.

В настоящее время не представляется возможным отделить благотворительные пожертвования от спонсорских средств, так как в формах федерального статистического наблюдения (8-НК, 9-НК и др.) эти финансовые поступления представлены суммарным показателем.

За четверть века рыночных преобразований так и осталась неразвитой институциональная среда для наращивания объема благотворительных средств (закон о меценатстве и благотворительной деятельности предполагает только репутационные/имиджевые преференции без учета какой-либо существенной экономической составляющей). Корпоративные пожертвования сдерживаются отсутствием ощутимых налоговых преференций, а неблагоприятная экономическая конъюнктура сказывается на возможностях так называемой низовой благотворительности (пожертвования частных лиц и малого бизнеса). Малый бизнес и платежеспособный средний класс являются той необходимой капиллярной системой, которая обеспечивает круговорот благотворительных средств в развитых странах мира (не забывая при этом о прогрессивной шкале налогообложения, которая позволяет путем уменьшения налогооблагаемого вычета за счет благотворительных пожертвований попасть под меньшую ставку налога на доходы физических лиц. В результате выигрывает и налогоплательщик (он же и бла-

\section{Таблица 3}

Благотворительные и спонсорские средства учреждений культуры по видам культурной деятельности (2016 г.)

\begin{tabular}{|l|c|c|}
\hline $\begin{array}{c}\text { Вид культурной } \\
\text { деятельности }\end{array}$ & $\begin{array}{c}\text { Благотворительные } \\
\text { и спонсорские средства, } \\
\text { млрд руб. }\end{array}$ & $\begin{array}{c}\text { Доля благотворительных } \\
\text { и спонсорских средств в общей сумме } \\
\text { финансовых поступлений, \% }\end{array}$ \\
\hline \hline Театры & 1,7 & 2,1 \\
\hline Музеи & 1,5 & 2,2 \\
\hline $\begin{array}{l}\text { Концертные } \\
\text { организации }\end{array}$ & 0,3 & 1,1 \\
\hline Библиотеки & 0,2 & 0,4 \\
\hline Клубы & 1,3 & 1,1 \\
\hline
\end{tabular}


готворитель), и социально значимые отрасли, которые аккумулируют финансовые потоки за счет косвенной поддержки на основе развитой системы налоговых преференций).

Справедливости ради следует отметить, что неоднократно за рассматриваемый период предпринимались попытки по совершенствованию институциональной среды, в том числе в сфере культуры (например, политика «БОР» (бюджетирование, ориентированное на результат); создание фондов целевого капитала; партисипативное бюджетирование) (Музычук, 2016), однако имплантация западных механизмов поддержки без учета национальной специфики привела к возникновению институциональных ловушек (в трактовке академика В.М. Полтеровича), вследствие чего предпринимаемые преобразования можно охарактеризовать как «шаг вперед и два назад».

\section{Основные выводы}

Сфера культуры России плотно зажата между Сциллой прямого бюджетного финансирования и Харибдой отсутствия благоприятной институциональной среды для развития многоканальной системы финансирования.

На сегодняшний день в мире накоплен огромный арсенал инструментов и механизмов финансирования сферы культуры (Музычук, 2013). Однако в России в структуре финансовых поступлений культурных институций по-прежнему доминирует бюджетное финансирование. Несмотря на отдельные попытки построения многоканальной системы финансирования культуры, предпринятые за последнюю четверть века, палитра возможностей внебюджетного финансирования по-прежнему монохромна. В развитых странах многоканальная система финансирования культуры во многом зиждется на институтах гражданского общества, активной гражданской позиции населения, самоорганизации граждан (партисипативное бюджетирование, процентная филантропия (Хаунина, 2012, 2014) и др.)), а также сильном местном самоуправлении. Создание многоканальной системы финансирования культуры в России требует серьезной налоговой реформы, реформы местного само- управления, а также отхода от чисто бухгалтерского подхода, при котором развитие тормозится в угоду поддержания существующего статус-кво.

\section{ЛИТЕРАТУРА}

Музычук В.Ю. (2013). Государственная поддержка культуры: ресурсы, механизмы, институты. СПб.: Нестор История.

Музычук В.Ю. (2016). Партисипативное бюджетирование: институты гражданского общества в реализации социально значимых проектов / / Вестник Института экономики РАН. № 3. С. 38-52.

Музычук В.Ю. (2017). Государственный патернализм в сфере культуры: что не так с установками патера в России? Научный доклад. Препринт. М.: Институт экономики РАН.

Рубинштейн А.Я., Городецкий А.Е. (2017). Некоторые аспекты экономической теории государства. Научный доклад. Препринт. М.: Институт экономики PAH.

Хаунина Е.А. (2012). «Процентная филантропия» - проблемы трансплантации успешного института финансовой поддержки культурной деятельности. В сб.: «Культура и рынок. Опекаемые блага». Рубинштейн А.Я., Музычук В.Ю. (ред.). СПб.: Алетейя. С. 164-179.

Хаунина Е.А. (2014). От церковного налога к институту индивидуальных бюджетных назначений // Журнал Новой экономической ассочиаиии. № 4 (24). C. 200-205.

Поступила в редакиию 15 декабря 2018 г.

REFERENCES (with English translation or transliteration)

Khaunina E.A. (2012). Percentage PhilanthropyProblems of Transplantation of a Successful Institution of Financial Support for Cultural Activities. In: "Culture and Market. Patronized Goods". Rubinstein A.Ya. 
Muzychuk V.Yu. (eds). Saint Petersburg: Aletejya, 164-179 (in Russian).

Khaunina E.A. (2014). From Church Tax to the Institution of Budget Allocation. Journal of the New Economic Association, 4 (24), 200205 (in Russian).

Muzychuk V.Yu. (2013). Public Support for the Arts and Culture: Resources, Mechanisms, Institutions. Saint Petersburg: Nestor Istorija (in Russian).

Muzychuk V.Yu. (2016). Participatory Budgeting: Civil Society Institutions in Realization of Socially Significant Projects. Vestnik
Instituta Ekonomiki Rossiyskoy akademii nauk, 3, 38-52 (in Russian).

Muzychuk V.Yu. (2017). State Paternalism in the Cultural Sector: What's Wrong with the Guidelines of the Patron in Russia? Working paper. Preprint. Moscow: Institute of Economics RAS (in Russian).

Rubinstein A.Ya., Gorodetskiy A.E. (2017). Some Aspects of the Economic Theory of the State. Working paper. Preprint. Moscow: Institute of Economics RAS (in Russian).

Received 15.12.2018

\section{V.Yu. Muzychuk} Institute of Economics RAS, State Institute for Art Studies, Moscow, Russia

\section{Financing of the Arts and Culture in Russia: A Step Forward and Two Back...}

Abstract. The article analyzes cultural expenditures in Russia over the past two decades and more, both in the sphere, and in the context of the types of cultural activities. The paper also analyzed the possibilities of public cultural institutions to earn incomes, as well as to attract charities and sponsorship by type of institutions (theaters, concert organizations, museums, libraries and recreational centers). The current situation with financing of the arts and culture in Russia is characterized with: retention of the "residual principle" of financing, low priority of culture in the macroeconomic policy of the state, the prevalence of direct budget funding, the imperfection of the institutional environment for attracting additional sources of public support for the arts and culture. Despite sporadic attempts to build a multichannel system for financing of the arts and culture over the last quarter of a century, the palette of extrabudgetary funding opportunities is still monochrome. Creating a multichannel system for financing of the arts and culture in Russia requires serious tax reform, local government reform, and a departure from a purely accounting approach, in which development is hampered in favor of maintaining the existing status quo.

Keywords: cultural economics, public support for the arts and culture, cultural expenditures, cultural policy, charities and sponsorship in the arts and culture.

JEL Classification: Z1, Z18.

DOI: $10.31737 / 2221-2264-2019-41-1-10$ 